\title{
The preparation effect in task switching: Carryover of SOA
}

\author{
ERIK M. ALTMANN \\ Michigan State University, East Lansing, Michigan
}

\begin{abstract}
A common finding in task-switching studies is switch preparation (commonly known as the preparation effect), in which a longer interval between task cue and trial stimulus (i.e., a longer stimulus onset asynchrony, or SOA) reduces the cost of switching to a different task. Three experiments link switch preparation to within-subjects manipulations of SOA. In Experiment 1, SOA was randomized within subjects, producing switch preparation that was more pronounced when the SOA switched from the previous trial than when the SOA repeated. In Experiment 2, SOA was blocked within subjects, producing switch preparation but not on the first block of trials. In Experiment 3, SOA was manipulated between subjects with sufficient statisticalpower to detect switch preparation, but the effect was absent. The results favor an encoding view of cognitive control, but show that any putative switching mechanism reacts lazily when exposed to only one SOA.
\end{abstract}

It makes intuitive sense to think that when people know they are about to begin a task, they prepare themselves to perform it. The preparation may take physical forms, as when we assemble the materials needed to work in the garden or tackle a building project, but it can take mental forms as well, as when one thinks through a lecture before giving it. Evidence from the task-switching literature suggests that this mental preparation extends to even much simpler tasks and shorter time periods. Typical tasks in a task-switching study might be to judge whether a digit is odd or even or greater or less than some criterion value, with some form of cue given before each trial as to what task to perform. The general finding is that time to perform a trial-to categorize a digit as "odd" or "even," say-is anywhere from about 20 to $300 \mathrm{msec}$ slower when a different task - to judge a digit as high or low, say-was performed on the preceding trial. This latency switch cost is often accompanied by an increase in errors. With time to prepare for the upcoming task-with a stimulus onset asynchrony (SOA) between a task cue and trial stimulus - these switch costs are typically reduced, suggesting that people use the SOA at least to begin to establish a mental context appropriate to perform the cued task. This switch preparation effect, in which longer SOAs (up to half a second or more) reduce switch cost, is robust enough that it has graduated to the list of "basic phenomena" in task switching as inventoried recently by Monsell (2003). Similarly, in another survey, Logan (2003) writes that switch cost "is largest when the SOA is zero and decreases as SOA increases,

This research was supported in part by a grant from the Office of Naval Research. Thanks to Iring Koch, Gordon Logan, and an anonymous reviewer for their detailed reviews. Correspondence should be addressed to E. M. Altmann, Department of Psychology, Michigan State University, East Lansing, MI 48824 (e-mail: ema@msu.edu). sometimes disappearing at the longest SOA" (p. 47). This assertion is made without attribution, suggesting again that this is a broadly accepted finding.

Table 1 summarizes human behavioral studies that have manipulated SOA (preparation time) and indicates for each experiment whether switch cost was affected. In most cases, the manipulation was within subjects (blocked or randomized) and did in fact produce switch preparation. The preference for within-subjects designs is unsurprising, given their improved statistical power; nonetheless, such designs leave open the possibility that exposure to different levels of the independent variable produce carryover effects that confound interpretation of the results (Poulton, 1982). In the case of switch preparation, it is at least conceivable that, exposed to random or perhaps even blocked levels of SOA, the system will adopt compromise settings of the parameters that govern preparatory processing in such a way that the anticipated effects of the manipulation are not realized. Indeed, Koch (2001) thought to compare results from two of his experiments that differed in SOA. Treating experiment as a between-subjects factor, he found no reliable effect of SOA $(F<1)$. Thus, one goal of the present study was to replicate Koch's (2001) finding, using new tasks and stimulus materials and addressing carryover effects of SOA as the main focus.

Table 1 supports the inference that if the preparation effect is evident in a given study, then SOA was manipulated within subjects. It also shows some evidence on the contrapositive- that when SOA is manipulated between subjects, switch preparation should be absent. Koch (2001, as noted above) and Arrington (2002, Experiment 2) both manipulated SOA between subjects and found no switch preparation. Sohn and Anderson (2003) manipulated SOA between subjects and found switch preparation, but crossed their manipulation with a within-subjects manipulation of task "foreknowledge" —on alternating 
Table 1

Task-Switching Studies Manipulating Stimulus Onset Asynchrony (SOA) Between Task Cue and Trial Stimulus

\begin{tabular}{|c|c|c|c|c|}
\hline Study Author & Experiment & Paradigm & $\begin{array}{c}\text { SOA } \\
\text { Manipulation }\end{array}$ & $\begin{array}{c}\text { Switch } \\
\text { Preparation? }\end{array}$ \\
\hline Arrington (2002) & 2 & exp. cuing & BS & no \\
\hline De Jong (2000) & 1,2 & alt. runs & WS & yes \\
\hline De Jong (2001) & 2 & alt. runs & WS & yes \\
\hline De Jong et al. (1999) & 2 & alt. runs & WS & yes \\
\hline Fagot (1994) & 3 & alt. runs & WS & yes \\
\hline Garavan (1998) & 2 & exp. cuing & WS & yes \\
\hline Goschke (2000) & 1 & precued pair & WS blocked & yes \\
\hline Hahn et al. (2003) & 1 & exp. cuing & WS blocked & yes \\
\hline Ivry \& Hazeltine (2000) & 1,2 & precued pair & WS & yes \\
\hline Koch (2001) & 1 vs. 3 & exp. cuing & BS & no \\
\hline Koch (2001) & 4 & exp. cuing & WS & yes \\
\hline Koch (2003) & 1 cue & alt. exp. & WS blocked & yes \\
\hline Koch (2003) & 1 no cue & alt. runs & WS blocked & no \\
\hline Kramer et al. (1999) & 2,3 & alt. runs & WS blocked & yes \\
\hline Kray \& Lindenberger (2000) & 1 & alt. runs & WS blocked & yes \\
\hline Logan \& Bundesen (2003) & 1 to 5 & exp. cuing & WS & yes \\
\hline Mayr (2002) & 1 & exp. cuing & WS & yes \\
\hline Mayr \& Keele (2000) & 4 & exp. cuing & WS & yes \\
\hline Mayr \& Kliegl (2003) & 2 & exp. cuing & WS blocked & yes \\
\hline Meiran (1996) & 1 to 5 & exp. cuing & WS & yes \\
\hline Meiran (2000a) & 1,2 & exp. cuing & WS & yes \\
\hline Meiran (2000b) & 1 & exp. cuing & WS & yes \\
\hline Meiran et al. (2000) & $2,3,4$ & exp. cuing & WS & yes \\
\hline Meiran \& Marciano (2002) & 1 & exp. cuing & WS & yes \\
\hline Monsell, Sumner, \& Waters (2003) & 1,2 & alt. runs & WS blocked & yes \\
\hline Nieuwenhuis \& Monsell (2002) & 1 & alt. runs & WS blocked & yes \\
\hline Rogers \& Monsell (1995) & 2 & alt. runs & WS & no \\
\hline Rogers \& Monsell (1995) & 3 & alt. runs & WS blocked & yes \\
\hline Schuch \& Koch (2003) & 1 & exp. cuing & WS blocked & yes \\
\hline Sohn \& Anderson (2001) & 1,2 & precued pair & WS blocked & yes \\
\hline Sohn \& Anderson (2003) & 1 & precued pair & $\mathrm{BS}$ & no \\
\hline Tornay \& Milan (2001) & 1,2 & exp. cuing & WS blocked & yes \\
\hline
\end{tabular}

Note-SOA, stimulus onset asynchrony; alt. runs, alternating runs, in which tasks alternate in predictablelength runs (e.g., AABBAABB . . .); exp. cuing, explicit cuing, in which a task cue is presented before each trial (as here); precued pair, cues for each trial of a two-trial sequence appear together before the sequence; alt. exp., alternating runs with explicit cue; WS, within subjects; BS, between subjects. Switch preparation is the effect of SOA on switch cost, defined here to include cue-switch cost (Mayr \& Kliegl, 2003). For brevity, neuroimaging and animal studies are not included.

blocks, participants received no task cue before stimulus onset. Thus, the opportunity to prepare during the SOA was effectively nullified on alternating blocks, so this study may not contradict the notion that between-subjects SOA manipulations fail to produce switch preparation.

Apart from the impact of experimental design, there are also open theoretical questions about the processes underlying switch preparation that might be masked by the seeming uniformity of the preparation effect. One conception of the underlying process is that "a little signal person in the head" (Rogers \& Monsell, 1995) performs "a sort of mental 'gear changing"” (Monsell, 2003) to reconfigure the system. According to this reconfiguration view, the switching mechanism benefits from a longer SOA because it can get an early start on "reconnecting and reconfiguring the various modules in our brains, so as to perform one task rather than another" (Monsell \& Driver, 2000). The resulting prediction is that a longer SOA should reduce switch cost, which, as Table 1 indicates, appears to be the usual finding.
However, another perspective is that the functional processes in task switching are more basic perceptual or memory processes that transform an external cue into a mental representation that effectively guides behavior. From this perspective, whether the cue switches the task is secondary to internal cognitive constraints, such as proactive interference from past cues (Allport \& Wylie, 2000; Altmann, 2002; Altmann \& Gray, 2002). I will refer to this as the encoding view, intentionally leaving open, for present purposes, whether the functional process is perceptual encoding, memory encoding, or some combination. Support for the encoding view comes from studies that disentangle task switching and cue switching (Logan \& Bundesen, 2003; Mayr \& Kliegl, 2003), which show that cue switching explains much of switch cost. (Note that Mayr and Kliegl attribute the cost of cue processing to memory retrieval rather than encoding, but retrieval and encoding are similar if interpreted as processes that increase the activation of a memory representation; Altmann, 2002.) Also, although perfectly 
able to switch tasks, monkeys seem to exhibit no switch cost (Stoet \& Snyder, 2003), suggesting that a switching mechanism is not strictly necessary in functional terms. Other evidence comes from studies in which a run of multiple trials follows a task cue. In these extended-runs paradigms, the first trial of the run is uniformly slower than subsequent trials, whether or not the cue immediately preceding that trial switched the task (Allport \& Wylie, 2000; Altmann \& Gray, 2002; Gopher, Armony, \& Greenshpan, 2000; Kramer, Hahn, \& Gopher, 1999). This substantial first-trial cost, which is much larger than switch cost, suggests that some common process applies to all task cues, whether or not they switch the task. From this perspective, switch cost can be interpreted as measuring the facilitation of this task-neutral process by repetition priming from the previous task representation, a point I return to in the General Discussion.

The reconfiguration view and the encoding view make different predictions for which measures should be affected by preparation time. The reconfiguration view suggests that longer SOAs should facilitate performance on switch trials and hence should reduce switch cost (which compares performance on switch trials with performance on repeat trials). The encoding view suggests that longer SOAs should benefit both switch trials and repeat trials, because encoding processes run on both (with switch cost possibly also being affected, depending on ancillary assumptions).

The present experiments address two questions that flow from this discussion. The first is whether switch preparation hinges on participants being exposed to multiple levels of SOA. Specifically, when participants see only one level, as in a between-subjects design, the question is whether switch preparation vanishes, as in Koch's (2001) analysis and Arrington's (2002) Experiment 2. The second question concerns the performance measures affected by SOA manipulations. The conventional switch preparation effect just discussed refers to the reduction of switch cost with longer SOA, but there is also a generic preparation effect, in which a longer SOA reduces overall response latency on switch and repeat trials. Evidence for some form of generic preparation can be found in many task-switching studies (e.g., Dreisbach, Haider, \& Kluwe, 2002; Koch, 2001; Mayr \& Keele, 2000; Sohn \& Carlson, 2000), so reproducing this effect here would not be particularly revelatory. However, a more interesting question is whether switch preparation and generic preparation are triggered by the same conditions. If so, this would support the view that some process like encoding is common to switch and repeat trials, and that this process is what can benefit from preparation time. Whether some such process can explain switch cost as well is not directly addressed by these experiments, but in the General Discussion I will argue that the encoding view does in fact offer a more parsimonious account of the present empirical results.

The three experiments reported here all employ the explicit cuing paradigm (e.g., Logan \& Bundesen, 2003;
Meiran, 1996), in which a task cue and a trial stimulus are presented on each trial, separated by an SOA. All three experiments use the same materials and general procedure, and SOAs of 100 and $900 \mathrm{msec}$. The response-stimulus interval is constant at $1 \mathrm{sec}$, to control the amount of repetition priming from the previous trial (Meiran, 1996), which would otherwise confound the interpretation of SOA-induced changes in overall response latency. In Experiment 1, the two SOAs are randomized from trial to trial, in Experiment 2 they alternate in blocks, and in Experiment 3 they vary between subjects.

\section{EXPERIMENT 1}

This experiment was conducted to replicate switch preparation using materials and procedure that would carry over to Experiments 2 and 3 and to establish a baseline effect size for switch preparation for use in a power analysis in Experiment 3.

\section{Method}

Participants. Twenty undergraduates from Michigan State University participated in exchange for partial course credit. Data from 3 additional participants were excluded because their overall accuracy was below $90 \%$, the level at which the feedback given to participants asked them to be more accurate (see below).

Materials. A task cue was either the letter " $h$ " (meaning height) or the letter "w" (meaning width) presented in white in the middle of a dark computer display. Characters were displayed in 40-point Monaco font, producing physical dimensions of $7 \times 11 \mathrm{~mm}$ (" $h$ ") and $9 \times 8 \mathrm{~mm}$ ("w"). A trial stimulus was one of four rectangles formed by crossing vertical and horizontal dimensions of 2.5 and $5 \mathrm{~cm}$. Rectangles were drawn in gray (Macintosh Common Lisp * gray-color*) using a 5-pixel pen and were centered in the display so that they surrounded the task cue. Viewing distance was approximately $60 \mathrm{~cm}$. Under the $\mathrm{h}$ task, participants judged the vertical height of the rectangle (tall or short), and under the w task, participants judged the horizontal width of the rectangle (thick or thin). The same keys ("Z" and "/") of a QWERTY keyboard were used for both tasks, with the response-to-key mapping randomized between subjects. Stimulus presentation and response recording were controlled by Macintosh Common Lisp 4.3 software running on $600 \mathrm{MHz}$ G3 iMac computers under Mac OS 9.1.

Design and Procedure. Each session began with a training period, lasting roughly $5 \mathrm{~min}$, in which participants were introduced to the tasks and stimuli by on-line instructions, with the experimenter present to answer questions. The training period included a practice block in which labels on the display were available as reminders of the response-to-key mapping; participants were asked to memorize the mapping and were warned that the labels would vanish after the practice block. After the practice block, participants were told of the number of blocks to follow and were advised to take breaks if necessary during the feedback screens appearing between blocks. Participants were also asked to "work as quickly as possible while avoiding too many errors" throughout the actual experiment; thus, no explicit instructions were given, in this experiment, to make use of the SOA to prepare to perform the cued task.

Each trial began with onset of the task cue, followed by an SOA ( 100 or $900 \mathrm{msec}$ ), followed by onset of the trial stimulus. Task cue, SOA, and trial stimulus were selected randomly for each trial. Task cue and trial stimulus remained on the display together until the participant's response. There was no time limit on responses, and no feedback was given after individual trials. After a response, there was a response-cue interval equal to $1,000 \mathrm{msec}$ minus the SOA, 
producing a constant response-stimulus interval across the two SOAs.

Thirty-five trials constituted a block. After each block, participants received feedback consisting of their percent accuracy for the block and one of three messages. If they scored between $90 \%$ and $100 \%$, the feedback read, "Good! You scored < percent accuracy $>\%$." If they made no errors that block, the feedback read, "Great! You scored $100 \%$. See if you can go a little faster." If they scored below 90\%, the feedback read, "Your accuracy was $<$ percent accuracy $>\%$. Please try to be more accurate." There were 24 blocks, not including the practice block, with each session lasting roughly $30 \mathrm{~min}$.

The first five blocks (including the practice block) and the first five trials of each remaining block were excluded from analysis. Outlying response latencies were filtered within participants by taking the median of correct trials. Response latencies and errors were analyzed with analyses of variance (ANOVAs) on the variables continuity (switch, repeat), SOA (short, long), and task (height, width), all within subjects (in this experiment). An additional ANOVA tested for a simple effect of SOA on repeat trials, as evidence of generic preparation. (Testing the simple effect of SOA on switch trials seemed unnecessary because this would have been redundant with the combination of the simple effect on repeat trials and the continuity $\times$ SOA interaction in the full ANOVA.)

\section{Results}

Response latency data are presented in the top panel of Figure 1. Means of participant medians for switch and repeat trials are on the left, and switch cost (switch latency minus repeat latency) is on the right.

There was a main effect of continuity $[F(1,19)=32.9$, $p<.001]$, with switch trials $(712 \mathrm{msec})$ slower than repeat trials $(606 \mathrm{msec})$. There was also a main effect of SOA $[F(1,19)=41.3, p<.001]$, with short-SOA trials $(691 \mathrm{msec})$ slower than long-SOA trials $(626 \mathrm{msec})$. Finally, there was a main effect of task $[F(1,19)=13.9$, $p<.002$ ], with height trials $(677 \mathrm{msec})$ slower than width trials (641 msec).

The continuity $\times$ SOA interaction was reliable $[F(1,19)=25.6, p<.001]$, as is evident in the top right panel of Figure 1, which shows the marked difference in switch cost across SOAs. The continuity $\times$ task interaction was marginally reliable $[F(1,19)=3.6, p=.073]$, as was the continuity $\times \mathrm{SOA} \times$ task interaction $[F(1,19)=$ $3.8, p=.067]$. The SOA $\times$ task interaction was not reliable $(F<1)$.

Finally, for repeat trials there was a simple effect of SOA $[F(1,19)=5.7, p<.03]$, with short-SOA trials $(618 \mathrm{msec})$ slower than long-SOA trials $(594 \mathrm{msec})$. There was also a simple effect of task $[F(1,19)=7.7$, $p<.02]$, with height trials $(618 \mathrm{msec})$ slower than width trials $(594 \mathrm{msec})$. The SOA $\times$ task interaction was not reliable $(F<1)$.

Error data are presented in the top panel of Figure 2. Mean error rates for switch and repeat trials are on the left, and switch cost is on the right. There was a main effect of continuity $[F(1,19)=14.3, p<.002]$, with errors more frequent on switch trials $(2.9 \%)$ than on repeat trials $(1.6 \%)$. There was also a main effect of task $[F(1,19)=10.7, p<.005]$, with errors more frequent on height trials $(2.8 \%)$ than on width trials $(1.6 \%)$. No other main effects or interactions were reliable.

\section{Discussion}

Experiment 1 replicated switch preparation (Figure 1, top right panel) with the present materials and procedure. It also demonstrated generic preparation (Figure 1, top left panel), indicating at minimum that more than the switching mechanism is affected by preparation time; clearly some other process is able to make use of a longer SOA to accomplish work that would otherwise be charged to response latency.

To assess whether switch preparation here was caused by exposure to multiple SOAs, a separate analy sis was conducted with trials separated according to SOA continuitywhether the SOA on the current trial repeated or switched the SOA of the previous trial. The logic is that if switch preparation reflects a carryover effect of SOA, then it should attenuate with time since the system encountered the other SOA. The latency data, thus separated, are shown in Figure 3, with SOA switch data in the left panel and SOA repeat data in the right panel. (The error data show no reliable effects relevant to this analysis.) The effect of SOA continuity is evident in the difference in switch preparation across the two panels, with a reliable SOA continuity $\times$ (task) continuity $\times$ SOA interaction $[F(1,19)=9.9, p<.006]$. Thus, switch preparation was in fact more pronounced when the system had experienced the other SOA immediately before the current one. However, the attenuated switch preparation shown in the right panel of Figure 3 was nonetheless also reliable $[F(1,19)=6.8, p<.02]$, indicating that carryover effects of SOA reached beyond a single trial. This raises the question, addressed next, of whether this carryover effect might reach across entire blocks of trials.

\section{EXPERIMENT 2}

This experiment tested whether, if exposure to multiple SOAs causes switch preparation, SOA has a sufficiently long-lasting influence on configuration of lowlevel strategies that it can survive a block of 35 trials. Some studies have demonstrated switch preparation using a blocked manipulation of SOA (Table 1), so the question is whether the effect in these cases can also be attributed to carryover influence.

\section{Method}

Twenty new participants were recruited from the same subject pool; here, none had to be excluded for falling below $90 \%$ accuracy. Materials, procedure, and data filtering and analysis were as in Experiment 1, with the exception that SOA remained the same over a full block of 35 trials, alternating every block for the whole session, beginning with the practice block. SOA for the practice block was counterbalanced between subjects. No explicit mention was made to subjects of the blocking protocol.

\section{Results}

Response latencies and switch cost are presented in the middle panel of Figure 1.

There was a main effect of continuity $[F(1,19)=39.9$, $p<.001]$, with switch trials $(659 \mathrm{msec})$ slower than repeat trials $(570 \mathrm{msec})$. There was also a main effect of 

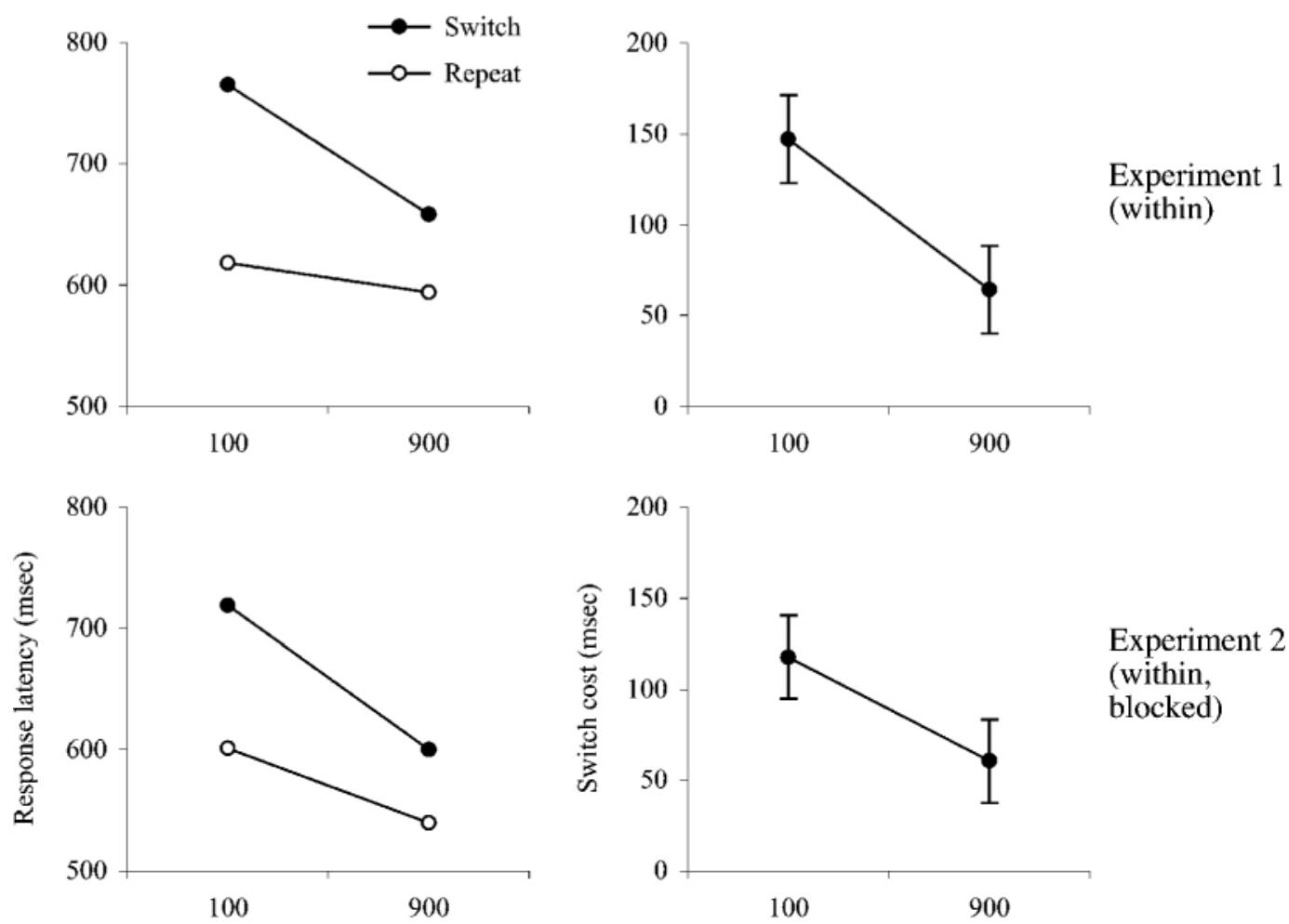

Experiment 2 (within, blocked)
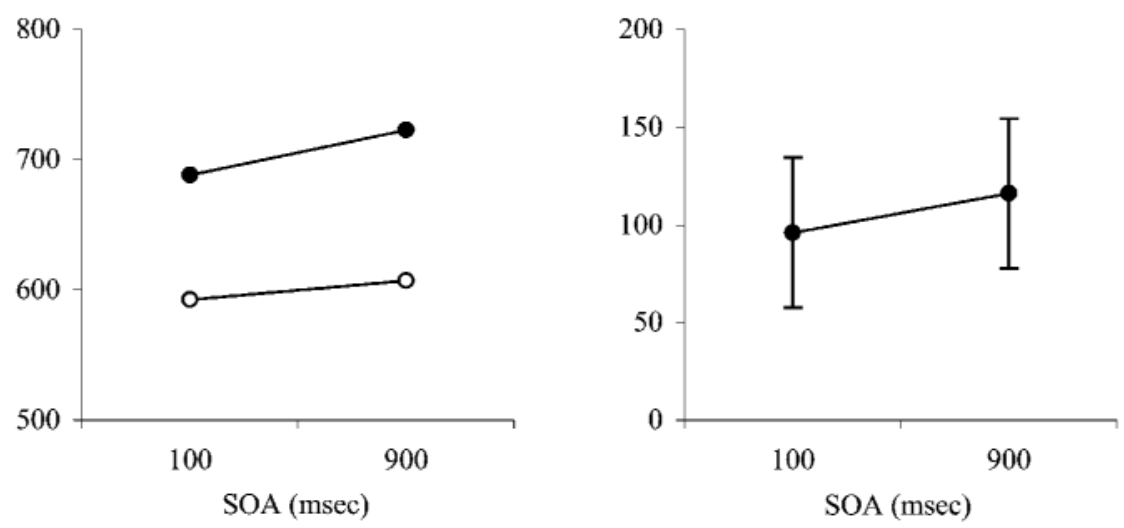

Experiment 3 (between)

Figure 1. Response latencies (left panels) and latency switch cost (right panels) for Experiments 1-3. Error bars are $95 \%$ confidence intervals computed from the error term of the continuity $\times$ SOA interaction (Loftus \& Masson, 1994). SOA, stimulus onset asynchrony, the interval between task cue onset and trial stimulus onset.

SOA $[F(1,19)=33.0, p<.001]$, with short-SOA trials $(660 \mathrm{msec})$ slower than long-SOA trials $(570 \mathrm{msec})$. Finally, there was a main effect of task $[F(1,19)=7.5, p<$ $.02]$, with height trials $(629 \mathrm{msec})$ slower than width trials $(600 \mathrm{msec})$.

The continuity $\times$ SOA interaction was reliable $[F(1,19)=13.7, p<.003]$, as is evident in the middle right panel of Figure 1, which like the top right panel shows a marked difference in switch cost across SOAs. The continuity $\times$ task interaction was marginally reliable $[F(1,19)=3.2, p=.092]$, as was the SOA $\times$ task interaction $[F(1,19)=4.3, p=.053]$. The continuity $\times$ $\mathrm{SOA} \times$ task interaction was not reliable $(p=.243)$.
Finally, for repeat trials there was again a simple effect of SOA $[F(1,19)=23.1, p<.001]$, with short-SOA trials $(601 \mathrm{msec})$ slower than long-SOA trials $(539 \mathrm{msec})$. The simple effect of task was marginal $[F(1,19)=3.3$, $p=.086]$, with height trials $(579 \mathrm{msec})$ slower than width trials $(561 \mathrm{msec})$. The SOA $\times$ task interaction was reliable $[F(1,19)=6.9, p<.02]$.

Error rates and error switch cost are presented in the middle panel of Figure 2. There was a main effect of continuity $[F(1,19)=8.1, p<.01]$, with errors more frequent on switch trials $(3.7 \%)$ than on repeat trials $(2.3 \%)$. The main effect of task was marginal $[F(1,19)=3.0, p=.097]$, with errors somewhat more frequent on the height task 

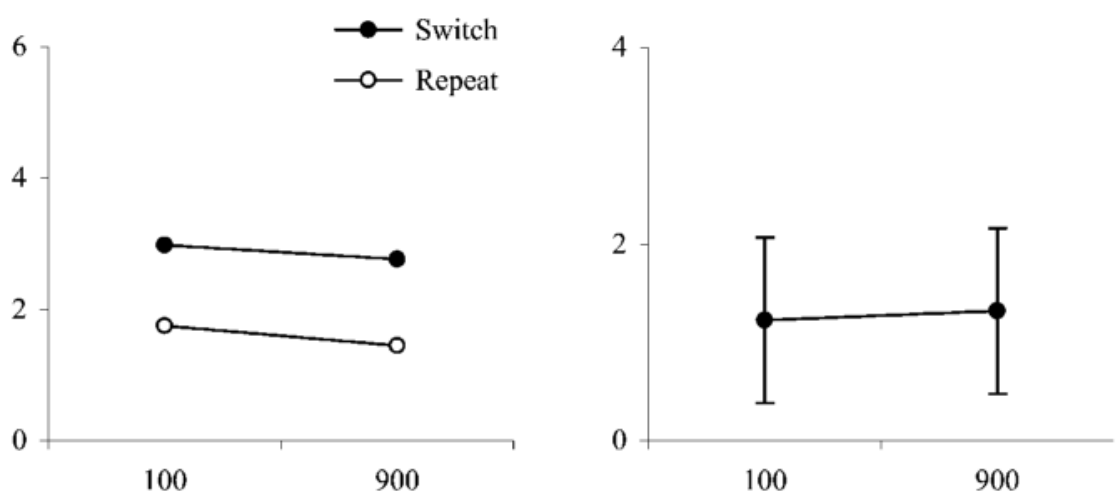
Experiment 1
(within)
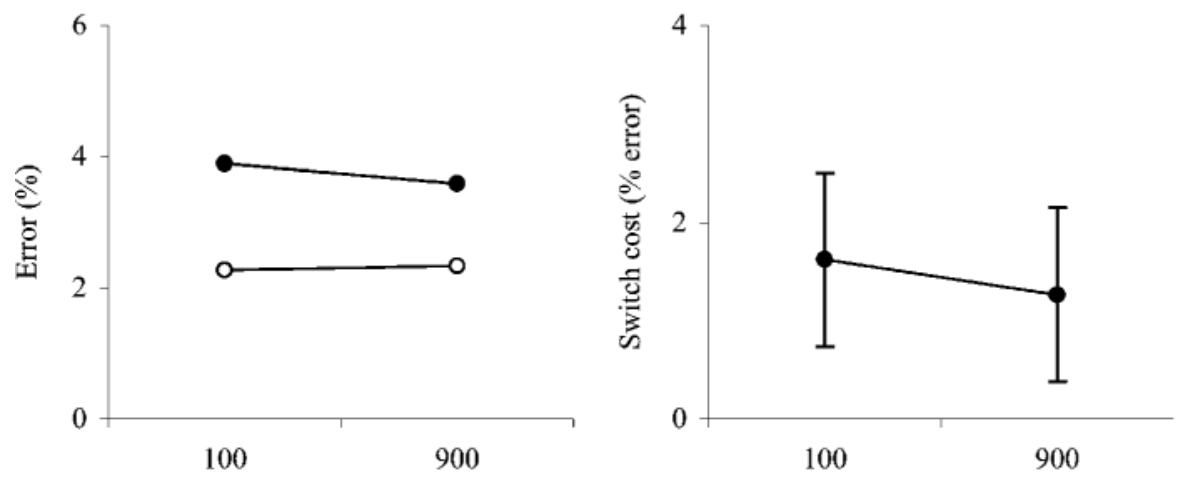

Experiment 2

(within, blocked)
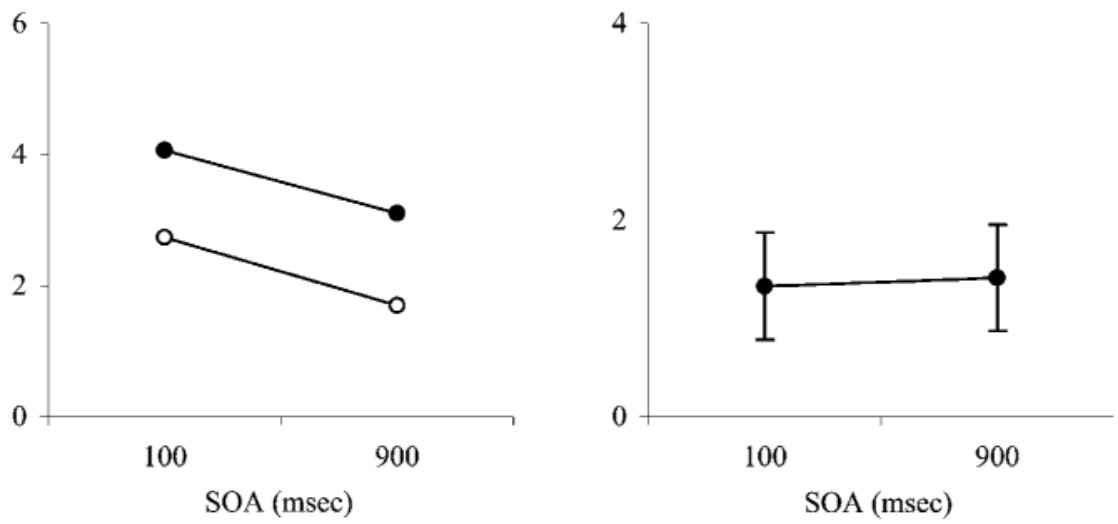

\section{Experiment 3} (between)

Figure 2. Error percentages (left panels) and error switch cost (right panels) for Experiments 1-3. Error bars are $95 \%$ confidence intervals computed from the error term of the continuity $\times$ SOA interaction (Loftus \& Masson, 1994). SOA, stimulus onset asynchrony, the interval between task cue onset and trial stimulus onset.

$(3.6 \%)$ than on the width task $(2.5 \%)$. No other effects were reliable.

\section{Discussion}

This experiment indicates that if switch preparation is caused by exposure to multiple levels of SOA, then blocking the different levels is sufficient; they need not be randomized within blocks. Both preparation effects were again evident, with longer SOA reducing switch cost (Figure 1, middle right panel) and also reducing response latencies generally (Figure 1, middle left panel).
As a preliminary assessment of whether switch preparation might vanish when SOA is manipulated between subjects, a separate analysis was conducted on the data from the practice block - the first block of the session, with no previous SOA to carry over. The (nonsignificant) trend for both latencies and errors was the opposite of switch preparation, with switch cost on short-SOA trials (242 msec, $2.8 \%$ error) smaller than switch cost on longSOA trials (376 msec, $3.0 \%$ error). A proper betweensubjects manipulation, with adequate statistical power to test a null effect, is discussed next. 


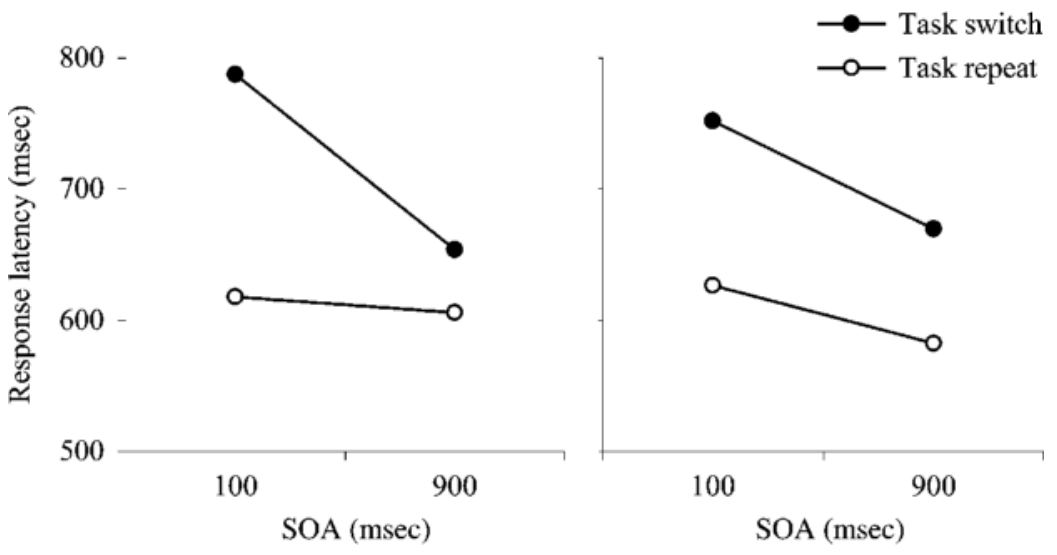

Figure 3. Experiment 1 response latencies, separated by SOA continuity. Left panel: data from trials on which the SOA switched from the previous trial. Right panel: data from trials on which the SOA repeated from the previous trial.

\section{EXPERIMENT 3}

This experiment was conducted against the background of the previous two to test whether switch preparation vanishes when subjects are exposed only to one level of SOA. If so, one theoretical interpretation would be that the switching mechanism has parameters that are altered in some fashion by exposure to multiple levels of SOA. Another question is whether generic preparation behaves the same way. If it also vanishes, this would indicate that the process whose parameters are affected by exposure to multiple SOAs is not necessarily a switching mechanism.

A final question addressed here relates to the role of instructional manipulations in moderating preparation effects. Participants were now asked explicitly to use the SOA to prepare for the upcoming trial. The goals were to begin to assess whether such instructions work and to rule out the possibility that null preparation effects could be attributed to lack of explicit instructions.

\section{Method}

Seventy-eight new participants were recruited from the same subject pool and were randomly assigned to the short- and longSOA conditions (for an $n$ per cell of 39). An additional 7 participants ( 4 in the short-SOA condition and 3 in the long-SOA condition) were excluded for falling below $90 \%$ accuracy overall. One additional participant was excluded (from the short-SOA condition) for having a median response latency that was more than $4 S D$ from the mean of participant medians. This exclusion affects none of the trends or inferential statistics described below, other than increasing the statistical power to detect a continuity $\times$ SOA interaction.

Materials, procedure, and data filtering and analysis were as in Experiment 1, with two critical exceptions. The first was that SOA was now manipulated between subjects. The second was that the training instructions to participants were modified in one specific way - to explicitly ask them to make use of the SOA to prepare for the upcoming task. The new instruction, verbatim, was as follows:

During the experiment, please try to work as efficiently as you can. Specifically, as soon as you see an instruction (h or w), please try to ready yourself mentally to classify the upcoming rectangle, so that when the rectangle appears a moment later you'll be able to respond as quickly as possible.

This instruction was presented after the practice block, so that participants would be able to interpret "a moment later" directly in terms of the SOA they had experienced.

\section{Results}

Response latencies and switch cost are presented in the bottom panel of Figure 1.

There was a main effect of continuity $[F(1,76)=62.2$, $p<.001]$, with switch trials $(705 \mathrm{msec})$ slower than repeat trials $(600 \mathrm{msec})$. Short-SOA trials $(640 \mathrm{msec})$ trended slightly faster than long-SOA trials $(665 \mathrm{msec})$, but this effect was not reliable $(F<1)$. There was again a main effect of task $[F(1,76)=18.8, p<.001]$, with height trials $(666 \mathrm{msec})$ slower than width trials $(640 \mathrm{msec})$.

The continuity $\times$ SOA interaction was not reliable $(F<1)$, as shown in the middle right panel of Figure 1, which, unlike the top and middle right panels, shows a slight trend for switch cost to increase at the longer SOA. The continuity $\times$ task interaction was reliable $[F(1,76)=$ $4.2, p<.05]$, as was the continuity $\times \mathrm{SOA} \times$ task interaction $[F(1,76)=4.6, p<.04]$. The SOA $\times$ task interaction was marginally reliable $[F(1,76)=4.3, p=.053]$.

No separate analysis was conducted for response latencies on repeat trials, since the trend was again in the wrong direction for switch preparation, with short-SOA trials $(592 \mathrm{msec})$ slightly faster than long-SOA trials (607 msec).

With the large number of participants and the trend toward an increase in switch cost at the longer SOA, it seems reasonable to accept the hypothesis that SOA had no effect on switch cost. Nonetheless, it is possible in principle that the between-subjects manipulation of SOA introduced so much additional variability that one should not accept the null hypothesis, because a between-subjects design would be incapable of detecting a switch prepa- 
ration effect. To address this possibility, a power analysis (adapted from D' Amico, Neilands, \& Zambarano, 2001) was conducted using means from Experiment 1 to estimate the effect size, and standard deviations and intercorrelations from Experiment 3 to estimate the variance. This procedure computes a power of .86 to detect a continuity $\times$ SOA interaction, which is well above the .8 level recommended by Cohen (1988) and Murphy and Myors (1998). Thus, even with the additional variance of a between-subjects manipulation, Experiment 3 had adequate statistical power to detect a preparation effect with high probability.

Error rates and error switch cost appear in the bottom panel of Figure 2. There was a main effect of continuity $[F(1,76)=48.3, p<.001]$, with errors on switch trials $(3.6 \%)$ more frequent than on repeat trials $(2.2 \%)$. Here there was a main effect of SOA $[F(1,76)=5.0, p<.03]$, with errors on short-SOA trials $(3.4 \%)$ more frequent than errors on long-SOA trials $(2.4 \%)$. The main effect of task was marginal $[F(1,76)=3.5, p=.067]$. No interactions were reliable (all $F \mathrm{~s}<1$ ).

\section{Discussion}

This experiment shows, with high confidence, that switch preparation vanishes when SOA is manipulated between subjects, even when participants are under what would appear to be "strong" (Koch, 2003) or "careful" (Nieuwenhuis \& Monsell, 2002) instructions to make use of the SOA to prepare for the upcoming trial. It is not the case that switch preparation was simply reexpressed in terms of error rates, since the error analysis (specifically, the continuity $\times$ SOA interaction) produced identical results. Nor is it the case that the range of SOAs $(100-900 \mathrm{msec})$ was too narrow for the effect to manifest, at least under the conventional wisdom that SOAs beyond $600 \mathrm{msec}$ or so fail to produce much further reduction in switch cost (Rogers \& Monsell, 1995).

Two important patterns in these data suggest that similar preparatory processing occurs on switch trials and repeat trials. In terms of response latencies, switch preparation and generic preparation vanished simultaneously. That is, longer SOAs failed to reduce switch cost (Figure 1, bottom right) and failed to reduce absolute response latencies (Figure 1, bottom left). Thus, just as both forms of preparation effect were present in Experiments 1 and 2, both were absent here, at least in terms of latencies. There was a preparation effect in terms of errors, with the longer SOA reducing the overall error rate but not error switch cost. This indicates that generic preparation can occur without switch preparation, a point further addressed in the General Discussion. These results are similar to those of Koch (2001) in that he also found generic preparation without switch preparation, but they differ in that he found a large (220-msec) effect in terms of response latencies (errors were not reported).

Finally, this experiment, in the context of the first two, suggests that explicit instructions to prepare during the
SOA may have little effect on participants' behavior, at least in comparison with whatever intrinsic incentives are induced by exposure to multiple SOAs.

\section{GENERAL DISCUSSION}

These experiments establish that switch preparationone of the "basic phenomena" identified by Monsell (2003) in his survey and a regularity cited by Logan (2003) in his-is contingent on experimental design, hinging on whether participants see more than one level of SOA. One might therefore label it a methodological artifact, though this could cut both ways; one might also label as artifact the laziness of the switching mechanism when exposed to only one SOA. Either way, the results show that the system has some control over preparatory processing in task switching and establish exposure to multiple SOAs as one way to induce the system to be more efficient in its use of available preparation time.

What are the underlying preparation processes, and which of their parameters changes when participants are exposed to multiple SOAs? Assuming that preparatory processes include a switching mechanism (Monsell, 2003), at minimum we can say that this mechanism is, by default, lazy. That is, when exposed to only one SOA, the system seems to squander it, whatever its duration. In contrast, when exposed to two (or presumably more) SOAs, the system for some reason makes better use of long SOAs when they present themselves.

How one interprets this change in the "eagerness" of a putative switching mechanism depends on how one interprets the mechanism's exact function. For example, in the simulation model of Sohn and Anderson (2001), which basically implements De Jong's (2000) failure-to-engage model, the switching process (an ACT-R production; see Anderson \& Lebiere, 1998) is charged with retrieving the current task from memory and installing it in the system's focus of attention. Each process in this model is assigned a priority (a utility, in ACT-R terms) that helps the system decide which process to select for execution on a given system cycle, when multiple processes are available (this is simply the conflict resolution process commonly found in production systems). These priorities are subject to noise from cycle to cycle, meaning that on a given cycle, a lower priority process may be selected in place of a higher priority process. This random variation in priorities causes switch preparation because the longer the SOA, the more system cycles occur (during the SOA) on which the switching process could be selected, increasing the overall probability that it will be selected before onset of the trial stimulus. To explain the absence of switch preparation in Experiment 3, one would have to assume that the switching process receives a very low selection priority-lower than any other process available during the SOA- when the system is exposed to only one SOA. (With stimulus onset, the switching process would then acquire a more urgent status, as the en- 
abling condition for further progress; De Jong, 2000.) There remains the functional question of how the system might benefit from increasing the priority of the switching process only when there are multiple SOAs. I will leave it to the modelers to speculate, but if no clear answer presents itself, this may indicate a shortcoming of this model's account of switch preparation.

Indeed, the present results suggest that generic preparation is more basic than switch preparation, raising the question of whether a switching mechanism is really needed to explain switch cost. Switch preparation implied generic preparation, but generic preparation occurred on its own (Experiment 3), consistent with other studies (Dreisbach et al., 2002; Koch, 2001; Sohn \& Carlson, 2000; Stoet \& Snyder, 2003). (Switch preparation occurs without generic preparation in alternatingruns studies, but this may only reflect how repeat latencies are measured in that paradigm, a point I return to below.) This dissociation suggests that generic preparation reflects the basic functional process, in which case facilitation of this process by repetition priming seems like an obvious candidate account of switch cost. Priming, or some related automatic or passive process, is responsible for some amount of switch cost, as measured both with cuing paradigms (Arrington, Altmann, \& Carr, 2003; Meiran, Chorev, \& Sapir, 2000; Sohn \& Anderson, 2001, 2003) and with alternating runs (Koch, 2003; Ruthruff, Remington, \& Johnston, 2001; Yeung \& Monsell, 2003), and although priming does not eliminate switch cost with longer intertrial intervals (Sohn \& Anderson, 2003), it can last for minutes (Allport \& Wylie, 2000; Waszak, Hommel, \& Allport, 2003) or in general for days (e.g., Buck-Gengler \& Healy, 2001), so a priming account is by no means ruled out. In the end, a priming account of switch cost, even if it must assume action at longer temporal intervals, may be more parsimonious than the reconfiguration view (Monsell, 2003), which requires a brand new mechanism to be added to the inventory just to explain switch cost.

A final point concerns an apparent conflict between the present results and one study listed in Table 1. Rogers and Monsell (1995, Experiment 2) failed to find switch preparation when SOA was randomized within subjects. Their explanation was also in strategic terms: "A sensible signal person would not pull the switch lever if there was any possibility of a train's running through the switch while the switching operation was still in progress, because the train would derail" (p. 218). Be that as it may, the story is complicated by the nature of the alternatingruns paradigm itself. This paradigm lacks a repeat trial immediately following a task cue and consequently requires use of (typically) the second of a run of trials as a baseline to estimate switch cost. The result is that "switch cost" as measured in this paradigm may confound switch cost proper, as measured by comparing switch and repeat trials that follow a task cue, with slowing effects common to the first trial of any run (Allport \& Wylie, 2000;
Altmann \& Gray, 2002; Gopher et al., 2000; Kramer et al., 1999). Thus, the Rogers and Monsell result may reflect less a conservative switching mechanism than some first-trial process, like generic preparation, behaving in ways that we do not yet understand. Moreover, the possibility that generic preparation falls entirely on the first trial of the run (because that is when the system encodes, or reencodes, the task for that run) may also explain why generic preparation is often absent in the alternatingruns paradigm (e.g., De Jong, 2000; Koch, 2003; Rogers $\&$ Monsell, 1995). If generic preparation falls on the first trial, then SOA-induced changes in that process will not be registered on the second (or later) trials of a run.

Several open questions will be important to address in future work, three of which are outlined here. First, an encoding model of the present effects, incorporating repetition priming as the source of switch cost, will be important to formalize and compare with models that attribute (some of) switch cost to nonpriming processes (De Jong, 2000; Gilbert \& Shallice, 2002; Kieras, Meyer, Ballas, \& Lauber, 2000; Sohn \& Anderson, 2001; Yeung $\&$ Monsell, 2003). Second and related, it will be important to be more precise about what "encoding" means. The finding that encoding cost increases as the cue degrades (Logan \& Bundesen, 2003) indicates that encoding is at least partly perceptual; to assess whether there is some kind of encoding involved in later, responseselection processes, it might serve to add distractors that require capacity to inhibit, and then measure whether this interferes with the process of interest (Lavie, 2000; Posner \& Boies, 1971). Third, the encoding model makes a prediction concerning generic preparation that will be important to test. If "encoding" means (in part) activating a memory representation to overcome proactive interference (Allport \& Wylie, 2000; Altmann, 2002), then when the task cue is a memory load-as, for example, when a sequence of uncued trials follows a cued trialit should be critical that the process complete. Memory load might then function like cue validity (Dreisbach et al., 2002; Ruthruff et al., 2001) in making generic advance preparation a good investment, and might thus reliably induce generic preparation (without switch preparation) even when SOA is manipulated between subjects.

In conclusion, the present results contribute both methodologically and theoretically to our understanding of cognitive control in task switching. Methodologically, they establish that carryover effects from different levels of SOA alter how task cues are processed, and by extension caution that other facets of cognitive control might be similarly affected by within-subjects designs. Theoretically, to understand the source of switch preparation, one must be able to manipulate it, and the present experiments identify a reliable causal variable. Given these results, any account of switch preparation-whether cast in terms of switching, encoding, or some other processwill have to address the strategic flexibility of that process and specify a causal link to exposure to multiple SOAs. 


\section{REFERENCES}

AllPort, A., \& Wylie, G. (2000). Task-switching, stimulus-response binding, and negative priming. In S. Monsell \& J. S. Driver (Eds.), Control of cognitive processes: Attention and performance XVIII (pp. 35-70). Cambridge, MA: MIT Press.

Altmann, E. M. (2002). Functional decay of memory for tasks. Psychological Research, 66, 287-297.

Altmann, E. M., \& GRAY, W. D. (2002). Forgetting to remember: The functional relationship of decay and interference. Psychological Science, 13, 27-33.

Anderson, J. R., \& Lebiere, C. (Eds.) (1998). The atomic components of thought. Mahwah, NJ: Erlbaum.

ARRINGTON, C. M. (2002). Explorations in task space: Similarity effects on task switching. Unpublished PhD dissertation, Michigan State University.

Arrington, C. M., Altmann, E. M., \& CARr, T. H. (2003). Tasks of a feather flock together: Similarity effects in task switching. Memory \& Cognition, 31, 781-789.

Buck-Gengler, C. J., \& Healy, A. F. (2001). Processes underlying long-term repetition priming in digit data entry. Journal of Experimental Psychology: Learning, Memory, \& Cognition, 27, 879-888.

COHEN, J. D. (1988). Statistical power analysis for the behavioral sciences (2nd ed.). Hillsdale, NJ: Erlbaum.

D'Amico, E. J., Neilands, T. B., \& Zambarano, R. (2001). Power analysis for multivariate and repeated measures analysis: A flexible approach using the SPSS MANOVA procedure. Behavior Research Methods, Instruments, \& Computers, 33, 479-484.

DE Jong, R. (2000). An intention-activation account of residual switch costs. In S. Monsell \& J. S. Driver (Eds.), Control of cognitive processes: Attention and performance XVIII (pp. 357-376). Cambridge, MA: MIT Press.

DE JoNG, R. (2001). Adult age differences in goal activation and goal maintenance. European Journal of Cognitive Psychology, 13, 71-89.

DE Jong, R., BERENDSEN, E., \& COOLS, R. (1999). Goal neglect and inhibitory limitations: Dissociable causes of interference effects in conflict situations. Acta Psychologica, 101, 379-394.

Dreisbach, G., Haider, H., \& KLUwe, R. H. (2002). Preparatory processes in the task-switching paradigm: Evidence from the use of probability cues. Journal of Experimental Psychology: Learning, Memory, \& Cognition, 28, 468-483.

FAGOT, C. (1994). Chronometric investigations of task switching. Unpublished PhD dissertation, University of California.

GARAVAN, H. (1998). Serial attention within working memory. Memory \& Cognition, 26, 263-276.

Gilbert, S. J., \& Shallice, T. (2002). Task switching: A PDP model. Cognitive Psychology, 44, 297-337.

Gopher, D., ARmony, L., \& GreEnShPAn, Y. (2000). Switching tasks and attention policies. Journal of Experimental Psychology: General, 129, 308-339.

GOSCHKE, T. (2000). Intentional reconfiguration and involuntary persistence in task set switching. In S. Monsell \& J. S. Driver (Eds.), Control of cognitive processes: Attention and performance XVIII (pp. 331-355). Cambridge, MA: MIT Press.

HAHn, S., ANdersen, G. J., \& Kramer, A. F. (2003). Multidimensional set switching. Psychonomic Bulletin \& Review, 10, 503-509.

IVRY, R. B., \& HAZELtine, E. (2000). Task switching in a callosotomy patient and in normal participants: Evidence for response-related sources of interference. In S. Monsell \& J. S. Driver (Eds.), Control of cognitive processes: Attention and performance XVIII (pp. 401423). Cambridge, MA: MIT Press.

Kieras, D. E., Meyer, D. E., Ballas, J. A., \& Lauber, E. J. (2000). Modern computational perspectives on executive mental processes and cognitive control: Where to from here? In S. Monsell \& J. S. Driver (Eds.), Control of cognitive processes: Attention and performance XVIII (pp. 681-712). Cambridge, MA: MIT Press.

$\mathrm{KoCH}$, I. (2001). Automatic and intentional activation of task sets. Journal of Experimental Psychology: Learning, Memory, \& Cognition, 27, 1474-1486.

$\mathrm{KoCH}, \mathrm{I}$. (2003). The role of external cues for endogenous advance re- configuration in task switching. Psychonomic Bulletin \& Review, 10, 488-492.

Kramer, A. F., HAHN, S., \& GOPHER, D. (1999). Task coordination and aging: Explorations of executive control processes in the task switching paradigm. Acta Psychologica, 101, 339-378.

KRAY, J., \& Lindenberger, U. (2000). Adult age differences in task switching. Psychology \& Aging, 15, 126-147.

LAVIE, N. (2000). Selective attention and cognitive control: Dissociating attentional functions through different types of load. In S. Monsell \& J. S. Driver (Eds.), Control of cognitive processes: Attention and performance XVIII (pp. 175-194). Cambridge, MA: MIT Press.

Loftus, G. R., \& MAsson, M. E. J. (1994). Using confidence intervals in within-subject designs. Psychonomic Bulletin \& Review, 1, 476490.

LogAn, G. D. (2003). Executive control of thought and action: In search of the wild homunculus. Current Directions in Psychological Science, 12, 45-48.

LogAn, G. D., \& BundeSEN, C. (2003). Clever homunculus: Is there an endogenous act of control in the explicit task-cuing procedure? Journal of Experimental Psychology: Human Perception \& Performance, 29, 575-599.

MAYr, U. (2002). Inhibition of action rules. Psychonomic Bulletin \& Review, 9, 93-99.

MAYR, U., \& KeELE, S. W. (2000). Changing internal constraints on action: The role of backward inhibition. Journal of Experimental Psychology: General, 129, 4-26.

MAYR, U., \& KLIEGL, R. (2003). Differential effects of cue changes and task changes on task-set selection costs. Journal of Experimental Psychology: Learning, Memory, \& Cognition, 29, 362-372.

MEIRAN, N. (1996). Reconfiguration of processing mode prior to task performance. Journal of Experimental Psychology: Learning, Memory, \& Cognition, 22, 1423-1442.

MEIRAN, N. (2000a). Intentional reconfiguration and involuntary persistence in task set switching. In S. Monsell \& J. S. Driver (Eds.), Control of cognitive processes: Attention and performance XVIII (pp. 377-399). Cambridge, MA: MIT Press.

MEIRAN, N. (2000b). Modeling cognitive control in task-switching. Psychological Research, 63, 234-249.

Meiran, N., Chore v,Z., \& SAPIR, A. (2000). Component processes in task switching. Cognitive Psychology, 41, 211-253.

MEIRAN, N., \& MARCIANO, H. (2002). Limitations in advance task preparation: Switching the relevant stimulus dimension in speeded same-different comparisons. Memory \& Cognition, 30, 540-550.

Monsell, S. (2003). Task switching. Trends in Cognitive Sciences, 7, 134-140.

Monsell, S., \& DRIVER, J. S. (2000). Banishing the control homunculus. In S. Monsell \& J. S. Driver (Eds.), Control of cognitive processes: Attention and performance XVIII (pp. 3-32). Cambridge, MA: MIT Press.

Monsell, S., Sumner, P., \& WATERs, H. (2003). Task-set reconfiguration with predictable and unpredictable task switches. Memory \& Cognition, 31, 327-342.

MURPHY, K. R., \& MYORS, B. (1998). Statistical power analysis: A simple and general model for traditional and modern hypothesis tests. Mahwah, NJ: Erlbaum.

NieuWenhuis, S., \& Monsell, S. (2002). Residual costs in task switching: Testing the failure-to-engage hypothesis. Psychonomic Bulletin \& Review, 9, 86-92.

Posner, M. I., \& Boies, S. J. (1971). Components of attention. Psychological Review, 78, 391-408.

Poulton, E. C. (1982). Influential companions: Effects of one strategy on another in the within-subjects designs of cognitive psychology. Psychological Bulletin, 91, 673-690.

Rogers, R. D., \& MONSELL, S. (1995). Costs of a predictable switch between simple cognitive tasks. Journal of Experimental Psychology: General, 124, 207-231.

RuthrufF, E., Remington, R. W., \& Johnston, J. C. (2001). Switching between simple cognitive tasks: The interaction of top-down and bottom-up factors. Journal of Experimental Psychology: Human Perception \& Performance, 27, 1404-1419. 
SCHUCH, S., \& KoCH, I. (2003). The role of response selection for inhibition of task sets in task shifting. Journal of Experimental Psychology: Human Perception \& Performance, 29, 92-105.

SOHN, M.-H., \& ANDERSON, J. R. (2001). Task preparation and task repetition: Two-component model of task switching. Journal of Experimental Psychology: General, 130, 764-778.

SOHN, M.-H., \& ANDERSON, J. R. (2003). Stimulus related priming during task switching. Memory \& Cognition, 31, 775-780.

SOHN, M.-H., \& CARLSON, R. (2000). Effects of repetition and foreknowledge in task-set reconfiguration. Journal of Experimental Psychology: Learning, Memory, \& Cognition, 26, 1445-1460.

Stoet, G., \& SNYDER, L. H. (2003). Executive control and task-switching in monkeys. Neuropsychologia, 41, 1357-1364.
Tornay, F. J., \& Milan, E. G. (2001). A more complete task-set reconfiguration in random than in predictable task switch. Quarterly Journal of Experimental Psychology, 54A, 785-803.

WASZAK, F., Hommel, B., \& Allport, A. (2003). Task-switching and long-term priming: Role of episodic stimulus-task bindings in taskshift costs. Cognitive Psychology, 46, 361-413.

YEUNG, N., \& MONSELL, S. (2003). Switching between tasks of unequal familiarity: The role of stimulus-attribute and response-set selection. Journal of Experimental Psychology: Human Perception \& Performance, 29, 455-469.

(Manuscript received May 23, 2003;

revision accepted for publication August 24, 2003.) 